\section{VHe 08}

SELECTIVE DECONTAMINATION IN NEUTROPENIC CANCER PATIENTS WITH CIPROFLOXACIN

D. Dennig, H.H. Fülle, K. P. Hellriegel

Infection has so far been a major cause of morbidity and mortality in neutropenic cancer patients. The risk of infection correlates with the degree and the duration of neutropenia. Prevention of infection is an aim which can be achieved in some instances by selective deconatmination. For selective decontamination, 27 patients received $500 \mathrm{mg}$ ciprofloxacin twice daily orally alone or in combination with nystatin, ketoconazole or amphotericin B. The patients suffered from acute nonlymphoblastic leukemia $(n=16)$, acute lymphoblastic leukemia $(n=7)$, blastic crisis of chronic myelogenous leukemia $(n=1)$ and other tumors $(n=3)$. The median duration of application of ciprofloxacin was 19 days with a range of 4 to 60 days. Under ciprofloxacin, fever did not appear in 14 patients, temperature over $38^{\circ} \mathrm{C}$ was observed in 13 cases. 5 of these patients had fungal infections, in 8 patients the origin of fever was unknown. 4 patients were treated additionally with systemic broad spectrum antibiotics; in 8 patients, broad spectrum antibiotics were given instead of ciprofloxacin. Elevated enzyme values at the start decreased during selective decontamination. In conclusion, ciprofloxacin is suited for selective decontamination in neutropenic patients. The occurence of bacterial infections in neutropenic patients can be reduced. Ciprofloxacin seems to be a safe drug: severe side effects were not observed, especially it does not seem to prolong the neutropenic phase. II. Innere Abteilung des Krankenhauses Moabit, Turmstr. 21, D-1000 Berlin 21

\section{VHe 09}

5 OLD PATIFNTS WTIH ACUIE ALFUCAEMLC LEUCOSIS

P. Beck, H. Gallenkamp

Introduction: Typical acute leucoses are rarely to observe in elder people, even less the aleucaemic variations. After we had studied some pancyto penias, anenias and thrombocytopenias of unknown reason without success we decided to inspect regularly the bone marrow when some of these peripheral blood alterations could be seer. Within 5 months 5 patients with acute aleucaemic lencaemias could be discovered. Al1 patients were elder than 66 years. In the peripheral blood blast cells could not be form.

\begin{tabular}{|c|c|c|c|c|c|}
\hline Patients data: & Pat. I & 2 & 3 & 4 & 5 \\
\hline leucosis & ALL & AML & ALLL & ANL & $\mathrm{AML}$ \\
\hline leading symptom & hemorrhoids & influen & bronchi & tis bronchitis & s leucocyto \\
\hline $\begin{array}{l}\text { leucocytes } \\
\left(\times 10^{3}\right)\end{array}$ & 1,3 & 2,6 & 9,8 & 4,2 & 43,6 \\
\hline $\begin{array}{l}\text { erythrocytes } \\
\left(x 1^{6}\right)\end{array}$ & 1,9 & 2,7 & 3,8 & 2,9 & 3,0 \\
\hline $\mathrm{MCV}(\mathrm{fl})$ & 133 & 109 & 86 & 94 & 95,3 \\
\hline $\begin{array}{l}\text { thrombocytes } \\
\left(x 10^{3}\right)\end{array}$ & 230 & 33 & 48 & 62 & 62 \\
\hline
\end{tabular}

$\begin{array}{llllll}\text { LDH (U/1) } & 166 & 238 & 671 & 353 & 1.163\end{array}$

Abdominal ultrasomd, $\mathrm{X}$-ray of the chest and other technical and blood examinations were normal. 2 patients are still alive, they get busulfan drugs. Pat. $2-4$ died after 10 days on the average. All diagnoses have been controlled by extern hematologists via bone marrow cytology/histology and peripheral blood smears.

Discussion: Perhaps in elder patients the sequestration of blast cells is disturbed at the bone marrow barrier, perhaps the blast cell populations have a very short temed life in the peripheral blond. An acute aleur caenic leucosis seems to be more often in these patients. The immune system may be less effective to prevent entering viral infections which induce blast cell fomation. This imune system is less effective to attack these blast cells as well. "Thus aleucaemic leucosis could mean that blast cells are not "forced" to leave the bone marrov. Anemias, thrombocyto penias or pancytopenias in elder patients should be examined to exclude aleucaenic leucosis.

Innere Abteilung, Ev. Krankenhaus Witten, Pferdebachstr.27 D-5810 Witten

\section{VHe 10}

LOW-DOSE ARA-C IN PATIENTS WITH AML AND MDS A. Heyll, C. Aul, U. Heyll, W. Schneider

During the last 18 months 20 patients with AML ( M1 $n=7, M 2 n=10, M 4 n=2, M 5 n=1$ ) and 4 patients with myelodysplasia ( CMML $n=1$, RAEB $n=2$, RAEB $-T n=1$ ) were treated with LD Ara-C. AML patients could be devided into 3 categories (1) de novo AML $n=10$ (2) AML in relapse $n=3$ and (3) AML secondary to MDS $n=7$. The median age of the AML group was 67 years (range: 41 80). To make possible out-patient care $s, c$. application of Ara-C at doses of $10 \mathrm{mg} / \mathrm{m}^{2} / 12 \mathrm{~h}$ was chosen. Therapy was continued for $8-21$ days.

All patients responding to LD Ara-C developed bone marrow hypoplasia and pancytopenia.

Therapy had to be interrupted in 14 cases because of progressive thrombocytopenia leading to intracerebral bleeding in 1 patient with RAEB. CR was obtained in 4 patients with de novo AMt. Duration of CR was $6+, 4,4,9$ months. PR was achieved in 1 patient with postmyelodysplastic AML. Presently (median time of observation 9 mo., range 6 - 20 mo.) 10 patients are still alive. Exept from the case mentioned above the other patients died of progression of leukemia.

In summary our results show that $C R$ rate and duration of AML patients treated with LD Ara-C is inferior to results of conventional aggressive chemotherapy. Therefore this regimen should be used only for patients in whom aggressive chemotherapy is contradicted. According to recent pharmacokinetic studies low efficiency and high rate of bone marrow hypoplasia might be due to s.c. administration.

Medizinische KIinik A der Universität Düsseldorf, Moorenstr. 5, D-4000 Düsseldorf 1

\section{VHe 11}

RADIOTHARAPY OF OSTEOLYTIC LESIONS IN MULTIPLE MYEIOMA.

V. Budach, G. Czeglarski, F. Wendt, M. Bamberg

Localized painful lesions of the bones and pathologic fractures are frequent in multiple myeloma. For these patients chemotherapy alone is insufficient. Additional local treatment modalities such as radiotherapy or surgery are necessary. In $94 \%$ of our patients radiotherapy was indicated due to localized severe pain, which was accompanied in $35 \%$ by osteolytic lesions, pathologic fractures or neurologic disturbances. 85 patients ( $55 \%$ males, $45 \%$ females, mean age: 59 years) have been irradiated with a 60-Co- or 137-0s-source. All received simultaneous chemotherapy. The most common treated region was the spine (54\%) followed by the thoracic wall (21\%) and pelvis $(14 \%)$. $54 \%$ of the patients needed irradiation of more than one site during illness. After doses of at least 24 Gy $81 \%$ of all patients were free or relieved of pain. Doses of more than 30 Gy were more effective and led to a higher percentage of asymptomatic patients. Following incomplete surgery of epidural tumours radiotherapy could permanently improve neurologic symptoms mildly to completely in 10 of 11 cases. Recalcification of osteolytic lesions occured in 12 of 16 patients when doses higher than 24 Gy were given. The mean survival period of all patients after diagnosis was 36 months, the 5- and 10year survival rates were $31 \%$ and $10 \%$ respectively. For long-term relievance of pain and neurologic deficits as well as a potential recalcification of osteolytic lesions we recommend the administration of target volume doses of 25-30 Gy in 3-4 weeks.

Strahlenklinik, Hufelandstr. 55, D-4300 Essen 